\title{
Isolation and quantitative analysis of metabolites from Scrophularia buergeriana and their hepatoprotective effects against HepG2 Cells
}

\author{
Hyeon Seon $\mathrm{Na}^{1,2} \cdot$ Seon Min $\mathrm{Oh}^{1,3} \cdot$ Woo Cheol Shin ${ }^{1,2} \cdot$ Jeon Hwang $\mathrm{Bo}^{3}$. \\ Hyoung-Geun $\mathrm{Kim}^{3}$ - Dahye Yoon ${ }^{1}$ - Seung Hwan Yang ${ }^{4}$ Young-Seob Lee ${ }^{1}$. \\ Geum-Soog Kim ${ }^{1} \cdot$ Nam-In Baek ${ }^{3} \cdot$ Moon-Soon Lee ${ }^{2} \cdot$ Dae Young Lee ${ }^{1}$
}

\section{현삼 (Scrophularia buergeriana)에서 분리한 화합물의 함량분석 및 간세포 보호 효과}

나현선 ${ }^{1,2} \cdot$ 오선민 ${ }^{1,3}$. 신우철 ${ }^{1,2}$. 황보전 ${ }^{3}$ - 김형 근 ${ }^{3} \cdot$ 윤다혜 $^{1} \cdot$ 양숭환 $^{4}$.

이영섭 ${ }^{1} \cdot$ 김 금숙 $^{1} \cdot$ 백남인 $^{3} \cdot$ 이문순 $^{2} \cdot$ 이대영 ${ }^{1}$

Received: 14 October 2019 / Accepted: 4 November 2019 / Published Online: 31 December 2019

(C) The Korean Society for Applied Biological Chemistry 2019

\begin{abstract}
The roots of Scrophularia buergeriana were extracted with $80 \%$ aqueous Methanol and the concentrates were partitioned into EtOAc, $n$ - $\mathrm{BuOH}$, and $\mathrm{H}_{2} \mathrm{O}$ fractions. The repeated silica gel or octadecyl $\mathrm{SiO}_{2}$ column, and medium pressure liquid chromatographies for the $n-\mathrm{BuOH}$ fraction led to isolation of phenylethanoid glycosides and iridoid glycosides. The chemical structures of these compounds were determined as harpagoside (1), angoroside C (2), aucubin (3) and acetoside (4) based on spectroscopic analyses including nuclear magnetic resonance and MS. A simple and efficient HPLC with UV detection method for the simultaneous determination of the four compounds (1-4) has been developed
\end{abstract}

Dae Young Lee $(\bowtie)$

E-mail: dylee0809@gmail.com

${ }^{1}$ Department of Herbal Crop Research, National Institute of Horticultural and Herbal Science, RDA, Eumseong 27709, Republic of Korea

${ }^{2}$ Department of Industrial Plant Science and Technology, Chungbuk National University, Cheongju 28644, Republic of Korea

${ }^{3}$ Graduate School of Biotechnology and Department of Oriental Medicine Biotechnology, Kyung Hee University, Yongin 17104, Republic of Korea

${ }^{4}$ Department of Biotechnology, Chonnam National University, Yeosu 59626, Republic of Korea

This is an Open Access article distributed under the terms of the Creative Commons Attribution Non-Commercial License (http://creativecommons. org/licenses/by-nc/3.0/) which permits unrestricted non-commercial use, distribution, and reproduction in any medium, provided the original work is properly cited. and applied to their content determination in the $S$. buergeriana. The roots were extracted by $80 \%$ methanol, and the contents of $\mathbf{1}$, 2, 3, and 4 were determined to $11.5,7.6,41.2$, and $4.8 \mathrm{mg} / \mathrm{g}$, respectively. Additionally, angoroside $\mathrm{C}$ (2) and acetoside (4) exhibited hepatoprotective effect against ethanol-induced hepatotoxicity in HepG2 cell line.

Keywords HepG2 · Iridoid · Phenylethanoid - Quantitative analysis $\cdot$ Scrophularia buergeriana

\section{서 론}

최근 식생활의 서구화, 알코올 섭취량의 증가 및 음주연령의 낮 아짐 등의 원인으로 간질환 환자가 증가하고 있다[1]. 정상적인 간은 중성지방(triglyceride)을 3-5\%를 함유하고 있지만, 지방간 은 지질대사의 장애로 간 조직에 중성지방이 $5 \%$ 이상 초과하 여 축적된 것으로 정의한다. 지방간은 알코올 이외에도 비만, 당뇨 등의 다양한 원인으로 발생되며 알코올성 지방간(alcoholic fatty liver disease; AFLD)과 비 알코올성 지방간(non-alcoholic fatty liver disease; NAFLD)으로 구분된다[2]. 일반적으로, 알코 올이 체내로 흡수되었을 때 시간의 경과에 따라 간의 효소작용 에 의해 해독이 되지만 알코올성 지방간은 만성적인 알코올 섭 취, 단기간 고용량의 음주 등으로 인한 간 기능의 손상과 장애 등을 유발하여 간의 비대화나 진행정도에 따라서 간세포의 괴 사 또는 간경화 등 고질적인 질환으로 발전될 수 있다[3]. 현삼 
(Scrophularia buergeriana)은 현삼과에 속하는 다년생 초본 식 물이며 한국, 중국 등 동아시아 지역에 널리 분포해 있다고 알 려져 있다[4]. 현삼의 약용부위는 건조한 뿌리를 사용하며, 일 반적인 모양은 불규칙하게 구부러지고 긴 원주형으로 길이 4$20 \mathrm{~cm}$, 지름 $1-3 \mathrm{~cm}$ 정도의 것으로 한약재료 사용한다[5]. 대한 약전에서는 현삼의 기원식물로 Scrophularia buergeriana Miquel의 뿌리를 한약재로 사용하며, 중국약전에는 Scrophularia ningpoensis Hemsley(중국현삼)을 생약제로 사용하고 있다. 동속 식물로는 큰개현삼 $(S$. nodosa), 토현삼 $(S$. koraiensis), 설령개현 삼(S. borlalin koreana), 섬현삼(S. kakesimensis) 등이 알려져 있다[6-7]. 한방에서는 현삼을 열병, 종창, 인두염, 신경염 및 후 두염 치료에 사용되어 왔으며, 다양한 약리작용이 있다고 알려 져 왔다[8-9]. 현삼을 이용한 생리활성 연구로는 신경보호 효과, 인지기능 개선 효과, 혈압강하 효과, 항염증 효과 등이 보고되 어 있다[10-14]. 현삼의 주요성분으로 iridoid 배당체와 phenylpropanoid 계열 화합물이 대표적으로 보고되어 있으며[15-18]. 현삼에서 분리보고 된 iridoid 및 배당체는 신경세포 보호, 항산 화, 항암, 항염증 활성 등이 보고되어 있다[19-22]. Phenylpropanoid 및 배당체의 생리활성 연구에는 신경세포보호, 항염증 및 항암 활성 등이 보고되어 있다[23-25].

본 연구에서는 선행 연구로부터 얻어진 현삼추출물의 간 기 능 개선 효능을 통하여, 현삼의 간기능개선 지표성분 설정 등 의 기초연구를 위하여 현삼에서 물질 분리 및 동정하였고, 화 합물의 함량을 확인하였으며 $\mathrm{HepG} 2$ 로 유발된 간암세포로부터 간 기능 개선의 활성여부를 확인하고자 연구를 진행하였다.

\section{재료 및 방법}

\section{실험재료}

실험에서 사용된 현삼의 뿌리는 2018년 11월에 안동시 성곡리 농가에서 수확한 1년근을 제공받아 실험을 진행하였으며, 표본 시료 (NIHHS18-11)는 국립원예특작과학원 인삼특작부에 보관 되어 있다.

\section{시약 및 기기}

Column chromatography (c. c.) 용 silica gel $\left(\mathrm{SiO}_{2}\right)$ resin은 Kiesel gel 60 (Merck, Darmstadt, Germany) 및 octadecyl $\mathrm{SiO}_{2}$ (ODS)은 Lichroprep RP-18 (40-60 $\mu \mathrm{M}$, Merck)을 사용하 였다. Thin layer chromatography (TLC)는 Kiesel gel 60 F254와 RP-18 F254s (Merck)을 사용하였다. 물질 정제에 사용 된 기기는 $\mathrm{YMC}$ LC-Forte/R (YMC Co., Ltd. Kyoto, Japan) 를 사용하였다. Nuclear magnetic resonance (NMR) 스펙트럼 은 $600.167 \mathrm{MHz}$ NMR (Agilent technologies, Santa Clara, CA, USA)을 사용하였고, IR (infra-red) 스펙트럼은 Perkin model 599B (Perkin-Elmer, Waltham, MA, USA)로 측정하였 다. 고분해능 질량값의 측정은 UPLC (Waters ACQUITY IClass, Waters Corp. Milford, MA, USA)가 부착된 HR-QTOF (Waters Xevo G2-S QTOF MS, Waters Corp)의 질량분 석기를 사용하였다. 정량분석에 사용된 장비는 Agilent 1200 series HPLC system (Agilent, Santa Clara, CA, USA)을 사용 하였다. 분석을 위한 증류수, Methanol $(\mathrm{MeOH})$ 및 Acetonitile은
HPLC grade (Fisher Scientific Korea Ltd., Seoul, Korea)를 사용하였으며, 분석 용매에 첨가한 Formic Acid는 $99.0 \%$ 의 Optima $^{\mathrm{TM}}$ LC/MS (Fisher Scientific) 급을 사용하였다. 그 외의 시약 및 용매는 모두 일급 이상의 시약을 구입하여 사용하였다. 세포 생존율 시험에서 사용한 DMEM 배지는 Lonza (Basel, Switzerland)에서 구입하였고, Fetal Bovine Serum (FBS)은 Hyclone (Logan, UT, USA)에서 구입하였다. 3-[4,5-dimetylthiazol2-yl]-2,5-diphenyltetrazolium bromide (MTT)와 DMSO는 SigmaAldrich (St. Louis, MO, USA)에서 구입하여 사용하였다.

\section{추출 및 성분 분리}

건조된 상태의 현삼 뿌리를 $5 \mathrm{~kg}$ 조분쇄하여 $80 \% \mathrm{MeOH}$ 수용 액에 24 시간 담가서 실온에서 3 회 추출하였다. 얻어진 추출물 은 합친 후 감압 농축하여 $\mathrm{MeOH}$ 추출물 $(\mathrm{SB}, 2.8 \mathrm{~kg})$ 을 얻었다. 얻어진 $\mathrm{MeOH}$ 추출물 $(1 \mathrm{~kg})$ 을 $\mathrm{EtOAc}(4 \mathrm{~L}) / \mathrm{H}_{2} \mathrm{O}(4 \mathrm{~L})$ 로 3 회 분배 추출하였고, 다시 $\mathrm{H}_{2} \mathrm{O}$ 층을 $n-\mathrm{BuOH}(4 \mathrm{~L})$ 로 3 회 분배 추 출하였다. 각 층을 감압 농축하여 $\mathrm{EtOAc}$ 분획 $(\mathrm{SBE}, 25.1 \mathrm{~g})$ 과 $n-\mathrm{BuOH}$ 분획 $(\mathrm{SBB}, 41 \mathrm{~g})$ 및 $\mathrm{H}_{2} \mathrm{O}$ 분획을 얻었다. 현삼 $n-$ $\mathrm{BuOH}$ 분획 $(\mathrm{SBB}, 41 \mathrm{~g})$ 에 대하여 $\mathrm{SiO}_{2}$ c.c. $(\Phi 8 \times 22.0 \mathrm{~cm}$, $\mathrm{CHCl}_{3}-\mathrm{MeOH}-\mathrm{H}_{2} \mathrm{O}=7: 3: 1$, 총 $10 \mathrm{~L}$ 사용)을 실시하여 총 9 개의 분획물(SBB-1-SBB-9)을 얻었다. 그 중 SBB-2 (2 g)을 $\mathrm{ODS}$ c.c $\left(\Phi 4.5 \times 15.0 \mathrm{~cm}, \mathrm{MeOH}-\mathrm{H}_{2} \mathrm{O}=1.5: 1\right.$, 총 $2 \mathrm{~L}$ 사용 $)$ 를 실시 하여 총 7개의 분획물(SBB-2-1-SBB-2-7)을 얻었다. 그 중 SBB-2-6 (1.3 g) 분획물에 대하여 중압분취장비(Medium pressure liquid chromatography, YMC LC-Forte/R)를 이용하여 분리를 진행하였다. 이때 사용된 컬럼은 YMC-Pack ODS-A $(20 \mathrm{~mm} \times$ $250 \mathrm{~mm}, 10 \mu \mathrm{m}$ )를 사용하였으며 이동상의 기울기 조건은 $\mathrm{A}$ $\left(\mathrm{H}_{2} \mathrm{O}\right): \mathrm{B}(\mathrm{MeOH})=45: 55$ 의 조건으로 30 분간 $10 \mathrm{~mL} / \mathrm{min}$ 의 유 속으로 $280 \mathrm{~nm}$ 파장에서 분리를 진행하였다. 총 3 개의 분획 (SBB-2-4-1-SBB-2-4-3)을 얻었고, 화합물 1 (SBB-2-4-2, 333.7 $\mathrm{mg}$ )를 분리하였다. SBB-5 (2 g)에 대하여 ODS c.c ( $\Phi$ 4.5×15.0 $\mathrm{cm}, \mathrm{MeOH}-\mathrm{H}_{2} \mathrm{O}=1: 1.5$, 총 $2 \mathrm{~L}$ 사용)를 실시하여 총 11 개의 분 획물(SBB-5-1-SBB-5-11)얻었으며 그중 화합물 2 (SBB-5-6, $139 \mathrm{mg}$ )를 분리하였다. SBB-9 $(2.5 \mathrm{~g})$ 에 대하여 MPLC를 이용 하여 분리를 진행하였다. 이때 사용된 컬럼은 YMC-Pack ODSA $(20 \mathrm{~mm} \times 250 \mathrm{~mm}, 10 \mu \mathrm{m})$ 를 사용하였으며 $10 \mathrm{~mL} / \mathrm{min}$ 의 유속 으로 $210 \mathrm{~nm}$ 파장에서 분리를 진행하였다. 이동상의 기울기 조 건은 $\mathrm{A}\left(\mathrm{H}_{2} \mathrm{O}\right): \mathrm{B}$ (Acetonitrile)=90:10의 조건에서 10 분간 $\mathrm{B}$ 를 $25 \%$ 로 증가시키고, 30 분간 $\mathrm{B}$ 를 $35 \%$ 로 증가시켰다. 총 10 개의 분획물(SBB-9-0-SBB9-9)을 얻었으며 화합물 3 (SBB-9-1, $673.5 \mathrm{mg}$ )을 분리하였다. SBB-9-7 (148.3 mg)에 대하여 MPLC 를 이용하여 분리를 진행하였다. 이때 사용된 컬럼은 YMC-Pack ODS-A $(20 \mathrm{~mm} \times 250 \mathrm{~mm}, 10 \mu \mathrm{m})$ 를 사용하였으며 이동상의 기 울기 조건은 $\mathrm{A}\left(\mathrm{H}_{2} \mathrm{O}\right): \mathrm{B}$ (Acetonitrile)=72:18 조건으로 60 분간 $15 \mathrm{~mL} / \mathrm{min}$ 의 유속으로 $203 \mathrm{~nm}$ 파장에서 분리를 진행하였다. 총 2개의 분획물을 얻었으며, 화합물 4 (SBB-9-7-1, $21.1 \mathrm{mg}$ )을 얻 었다.

화합물 1 (harpagoside) White amorphous powder; m.p. $128-131^{\circ} \mathrm{C}$; IR $\left(\mathrm{CaF}_{2}\right.$ window) $v_{\max } 3354,1690,1635,1512$ $\mathrm{cm}^{-1}$; ${ }^{1} \mathrm{H}-\mathrm{NMR}\left(600 \mathrm{MHz}, \mathrm{CD}_{3} \mathrm{OD}, \delta_{\mathrm{H}}\right)$ and ${ }^{13} \mathrm{C}-\mathrm{NMR}(150$ $\left.\mathrm{MHz}, \quad \mathrm{CD}_{3} \mathrm{OD}, \quad \delta_{\mathrm{C}}\right)$ in Table 1 ; Negative ESI/MS $\mathrm{m} / \mathrm{z}$ $493.1718[\mathrm{M}-\mathrm{H}]^{-}$. 
Table $1{ }^{1} \mathrm{H}-\mathrm{NMR}\left(\mathrm{CD}_{3} \mathrm{OD} ; 600 \mathrm{MHz}\right)$ and ${ }^{13} \mathrm{C}-\mathrm{NMR}$ spectral data $\left(\mathrm{CD}_{3} \mathrm{OD} ; 150 \mathrm{MHz}\right)$ of Compounds $\mathbf{1 - 4} \delta$ in ppm, $J$ in $\mathrm{Hz}$

\begin{tabular}{|c|c|c|c|c|c|c|c|c|}
\hline \multirow{2}{*}{ No. } & \multicolumn{2}{|c|}{ Compound 1} & \multicolumn{2}{|c|}{ Compound 2} & \multicolumn{2}{|c|}{ Compound 3} & \multicolumn{2}{|c|}{ Compound 4} \\
\hline & $\delta_{\mathrm{C}}$ & $\delta_{\mathrm{H}}(J$ in $\mathrm{Hz})$ & $\delta_{\mathrm{C}}$ & $\delta_{\mathrm{H}}(J$ in $\mathrm{Hz})$ & $\delta_{\mathrm{C}}$ & $\delta_{\mathrm{H}}(J$ in $\mathrm{Hz})$ & $\delta_{\mathrm{C}}$ & $\delta_{\mathrm{H}}(J$ in $\mathrm{Hz})$ \\
\hline 1 & 94.6 & 6.18 , br. $\mathrm{s}$ & 132.9 & - & 97.77 & $4.90, \mathrm{~d}, 7.2$ & 131.5 & - \\
\hline 2 & - & - & 112.8 & $6.71, \mathrm{~d}, 2.4$ & - & - & 115.4 & $6.69, \mathrm{~d}, 1.8$ \\
\hline 3 & 143.9 & $6.42, \mathrm{~d}, 6.6$ & 147.6 & - & 141.6 & $6.30, \mathrm{dd}, 6.0,1.8$ & 146.2 & - \\
\hline 4 & 106.9 & 4.94 , br. d, 6.0 & 147.4 & - & 105.7 & $5.09, \mathrm{dd}, 6.0,4.8$ & 144.8 & - \\
\hline 5 & 73.4 & - & 117.1 & $6.77, \mathrm{~d}, 7.8$ & 46.3 & $2.60, \mathrm{~m}$ & 116.6 & $6.67, \mathrm{~d}, 7.8$ \\
\hline 6 & 78.1 & $3.77, \mathrm{~d}, 3.6$ & 121.2 & $6.65, \mathrm{dd}, 7.8,2.4$ & 82.8 & 4.43 , overlapped & 123.3 & $6.57, \mathrm{dd}, 7.8,1.8$ \\
\hline 7 & 46.2 & $\begin{array}{c}2.27, \text { br. d, } 15.6 \\
2.02, \mathrm{dd}, 15.6,4.2\end{array}$ & 36.5 & $2.78, \mathrm{~m}$ & 130.3 & 5.76 , br. s & 36.7 & $2.80, \mathrm{~m}$ \\
\hline 8 & 88.8 & - & 72.1 & $4.00, \mathrm{~m}$ & 148.0 & - & 72.1 & $4.04, \mathrm{~m}$ \\
\hline 9 & 55.6 & $2.94, \mathrm{~s}$ & - & - & 47.9 & $2.89, \mathrm{dd}, 9.0,1.2$ & - & - \\
\hline 10 & 22.7 & $1.53, \mathrm{~s}$ & - & - & 62.7 & $\begin{array}{l}4.34, \mathrm{~d}, 15.0 \\
4.18, \mathrm{~d}, 15.0\end{array}$ & - & - \\
\hline $1^{\prime}$ & 100.0 & $4.63, \mathrm{~d}, 8.4$ & 105.0 & $4.34, \mathrm{~d}, 7.8$ & 99.9 & $4.68, \mathrm{~d}, 7.8$ & 104.2 & $4.38, \mathrm{~d}, 8.4$ \\
\hline $2^{\prime}$ & 74.6 & $3.23, \mathrm{dd}, 8.4,8.4$ & 76.2 & 3.54 , overlapped & 74.9 & $3.21, \mathrm{dd}, 7.8,7.8$ & 76.1 & 3.54 , overlapped \\
\hline $3^{\prime}$ & 78.2 & $3.41, \mathrm{dd}, 8.4,8.4$ & 81.6 & $3.83, \mathrm{dd}, 7.8,7.8$ & 77.9 & $3.36, \mathrm{dd}, 7.8,7.8$ & 81.6 & $3.81, \mathrm{dd}, 8.4,8.4$ \\
\hline $4^{\prime}$ & 71.8 & 3.32 , overlapped & 70.5 & $4.93, \mathrm{dd}, 7.8,7.8$ & 71.6 & 3.27 , overlapped & 70.6 & $4.92, \mathrm{dd}, 8.4,8.4$ \\
\hline $5^{\prime}$ & 77.6 & 3.30 , overlapped & 75.0 & 3.36 , br. dd, $7.8,6.0$ & 78.3 & 3.26 , overlapped & 76.3 & 3.39 , br. dd, $8.4,6.6$ \\
\hline $6^{\prime}$ & 62.9 & $\begin{array}{l}3.94, \mathrm{dd}, 12.0,1.2 \\
3.73, \mathrm{dd}, 12.0,6.0\end{array}$ & 69.1 & $\begin{array}{l}3.70 \text {, overlapped } \\
3.52 \text {, overlapped }\end{array}$ & 61.4 & $\begin{array}{l}3.85, \mathrm{dd}, 12.0,2.4 \\
3.64, \mathrm{dd}, 12.0,5.4\end{array}$ & 62.4 & $\begin{array}{l}3.62 \text {, overlapped } \\
3.52 \text {, overlapped }\end{array}$ \\
\hline $\mathbf{1}^{\prime \prime}$ & 135.9 & - & 127.6 & - & - & - & 127.7 & - \\
\hline $2^{\prime \prime}$ & 130.0 & $7.40, \mathrm{~m}$ & 111.8 & $7.15, \mathrm{~d}, 1.8$ & - & - & 117.2 & $7.05, \mathrm{~d}, 1.8$ \\
\hline $3^{\prime \prime}$ & 129.2 & $7.59, \mathrm{~m}$ & 149.3 & - & - & - & 147.0 & - \\
\hline $4^{\prime \prime}$ & 131.5 & 7.39 , overlapped & 151.0 & - & - & - & 149.9 & - \\
\hline $5^{\prime \prime}$ & 129.2 & $7.59, \mathrm{~m}$ & 116.4 & $6.78, \mathrm{~d}, 7.8$ & - & - & 115.5 & $6.78, \mathrm{~d}, 8.4$ \\
\hline $6^{\prime \prime}$ & 130.0 & $7.40, \mathrm{~m}$ & 124.4 & $7.03, \mathrm{dd}, 7.8,1.8$ & - & - & 121.4 & $6.96, \mathrm{dd}, 8.4,1.8$ \\
\hline $7^{\prime \prime}$ & 120.1 & $6.51, \mathrm{~d}, 15.6$ & 148.2 & $7.62, \mathrm{~d}, 15.6$ & - & - & 148.1 & $7.59, \mathrm{~d}, 16.2$ \\
\hline $8^{\prime \prime}$ & 146.1 & $7.67, \mathrm{~d}, 15.6$ & 115.0 & $6.33, \mathrm{~d}, 15.6$ & - & - & 114.8 & $6.27, \mathrm{~d}, 16.2$ \\
\hline 9" & 168.7 & - & 168.4 & - & - & - & 168.4 & - \\
\hline $1^{\prime \prime \prime}$ & - & - & 103.1 & $5.15, \mathrm{~d}, 1.2$ & - & - & 103.1 & $5.19, \mathrm{~d}, 1.8$ \\
\hline $2^{\prime \prime \prime}$ & - & - & 72.3 & $3.87, \mathrm{dd}, 3.0,1.2$ & - & - & 72.5 & $3.91, \mathrm{dd}, 3.6,1.8$ \\
\hline $3^{\prime \prime \prime}$ & - & - & 72.1 & $4.00, \mathrm{dd}, 7.8,3.0$ & - & - & 72.4 & $4.04, \mathrm{dd}, 7.8,3.6$ \\
\hline $4^{\prime \prime \prime}$ & - & - & 74.1 & 3.26 , overlapped & - & - & 73.9 & 3.29 , overlapped \\
\hline $5^{\prime \prime \prime}$ & - & - & 70.6 & 3.53 , overlapped & - & - & 70.7 & 3.57 , overlapped \\
\hline $6^{\prime \prime \prime}$ & - & - & 18.4 & $1.05, \mathrm{~d}, 6.0$ & - & - & 18.6 & $1.09, \mathrm{~d}, 6.6$ \\
\hline $1^{\prime \prime \prime \prime}$ & - & - & 104.1 & $4.19, \mathrm{~d}, 6.6$ & - & - & - & - \\
\hline $2^{\prime \prime \prime \prime}$ & - & - & 72.4 & 3.71 , overlapped & - & - & - & - \\
\hline $3^{\prime \prime \prime \prime}$ & - & - & 73.8 & 3.76 , overlapped & - & - & - & - \\
\hline $4^{\prime \prime \prime \prime}$ & - & - & 69.6 & 3.70 , overlapped & - & - & - & - \\
\hline $5^{\prime \prime \prime \prime}$ & - & - & 66.7 & $\begin{array}{l}3.83 \text {, overlapped } \\
3.52 \text {, overlapped }\end{array}$ & - & - & - & - \\
\hline OMe & - & - & 56.6 & $3.84, \mathrm{~s}$ & - & - & - & - \\
\hline $\mathrm{OMe}$ & - & - & 56.6 & $3.76, \mathrm{~s}$ & - & - & - & - \\
\hline
\end{tabular}

화합물 2 (angoroside C) White amorphous powder; m.p. $163-164{ }^{\circ} \mathrm{C}$; IR $\left(\mathrm{CaF}_{2}\right.$ window) $v_{\max } 3355,1710,1637,1601$, $1520 \mathrm{~cm}^{-1}$; ${ }^{1} \mathrm{H}-\mathrm{NMR}\left(600 \mathrm{MHz}, \mathrm{CD}_{3} \mathrm{OD}, \delta_{\mathrm{H}}\right)$ and ${ }^{13} \mathrm{C}-\mathrm{NMR}$ $\left(150 \mathrm{MHz}, \mathrm{CD}_{3} \mathrm{OD}, \delta_{\mathrm{C}}\right)$ in Table 1; Negative ESI/MS $\mathrm{m} / \mathrm{z}$ $783.2645[\mathrm{M}-\mathrm{H}]^{-}$.
화합물 3 (aucubin) White amorphous powder; m.p. 180-181 ${ }^{\circ} \mathrm{C} ; \quad[\alpha]_{\mathrm{D}}^{25}-150^{\circ} \quad\left(c=0.10, \mathrm{CH}_{3} \mathrm{OH}\right) ; \mathrm{IR}\left(\mathrm{CaF}_{2}\right.$ window $) v_{\max }$ $3355,1688,1630 \mathrm{~cm}^{-1}$; ${ }^{1} \mathrm{H}-\mathrm{NMR}\left(600 \mathrm{MHz}, \mathrm{CD}_{3} \mathrm{OD}, \delta_{\mathrm{H}}\right)$ and ${ }^{13} \mathrm{C}-\mathrm{NMR}\left(150 \mathrm{MHz}, \mathrm{CD}_{3} \mathrm{OD}, \delta_{\mathrm{C}}\right)$ in Table 1; Negative ESI/MS m/z $345.1211[\mathrm{M}-\mathrm{H}]^{-}$. 
화합물 4 (acetoside) White amorphous powder; m.p. 179$182{ }^{\circ} \mathrm{C}$; IR $\left(\mathrm{CaF}_{2}\right.$ window $) v_{\max } 3402,1710,1635,1600$, $1520 \mathrm{~cm}^{-1} ;{ }^{1} \mathrm{H}-\mathrm{NMR}\left(600 \mathrm{MHz}, \mathrm{CD}_{3} \mathrm{OD}, \delta_{\mathrm{H}}\right)$ and ${ }^{13} \mathrm{C}-\mathrm{NMR}$ $\left(150 \mathrm{MHz}, \mathrm{CD}_{3} \mathrm{OD}, \delta_{\mathrm{C}}\right)$ in Table 1; Negative ESI/MS m/z $623.1945[\mathrm{M}-\mathrm{H}]^{-}$.

\section{UPLC-ESI-Q-TOF/MS 분석}

분리된 화합물(1-4)을 $10 \mathrm{ppm}$ 의 농도로 희석하여 기기분석에 사 용하였다. UPLC가 부착된 Q-TOF/MS 장비를 및 ACQUITY $\mathrm{BEH} \mathrm{C} 18$ 컬럼 $(2.1 \mathrm{~mm} \times 100 \mathrm{~mm}, 1.7 \mu \mathrm{m})$ 을 사용하였고, 컬 럼의 오븐 온도는 $30{ }^{\circ} \mathrm{C}$ 로 설정하였다. 이동상 용매 시스템은 $0.1 \%$ acetic acid 수용액 (A)와 Acetonitrile (B)로 이루어졌으며, 이동상 조건은 $\mathrm{A}\left(\mathrm{H}_{2} \mathrm{O}\right): \mathrm{B}$ (Acetonitrile) $=95: 5$ 의 조건에서 7분 에 $\mathrm{B}$ 를 $33 \%$ 로 증가시키고, 8.5 분까지 $\mathrm{B}$ 를 $33 \%$ 로 유지시켰으 며, 10 분까지 $\mathrm{B}$ 를 $100 \%$ 로 증가시킨 후 15 분에 $\mathrm{B}$ 를 $5 \%$ 로 감 소시켰다. 컬럼 유속은 $0.5 \mathrm{~mL} / \mathrm{min}$ 이며, 주입량은 $2 \mu \mathrm{L}$ 이었다. 장비 분석 및 데이터 수집에는 UNIFI software (Ver 1.8.1, Waters Corp., Milford, MA, USA)를 사용하였다.

\section{HPLC를 이용한 정량분석}

분쇄한 현삼 시료 $50 \mathrm{~g}$ 을 농축용 플라스크에 평량하고 $70 \%$ $\mathrm{EtOH}(400 \mathrm{~mL})$ 을 첨가한 후 환류 냉각추출기에서 $70{ }^{\circ} \mathrm{C}$ 로 열 수추출을 2회 반복하고 얻어진 추출액을 감압 농축하였다. 농 축 후 남아있는 수분 제거를 위하여 동결건조를 진행하였으며 수율은 $53 \%$ 로 현삼 추출 동결건조물 $(26 \mathrm{~g})$ 얻었다. 얻어진 동 결 건조물을 $100 \mathrm{mg}$ 을 $1 \mathrm{~mL}$ 의 메탄올에 녹이고 $0.2 \mu \mathrm{m}$ 의 13 $\mathrm{mm}$ 디스크 필터(Chromdisc Co., Daegu, Korea)로 여과하여 $\mathrm{UV}$ 검출기가 장착된 $\mathrm{HPLC}$ 로 정량분석 하였다. 이때 사용된 컬럼은 역상 컬럼인 Phenomenex Luna C-18 (4.6 mm×150 $\mathrm{mm}, 5 \mu \mathrm{m})$ 을 사용하였다. 이동상 용매는 $0.1 \%$ formic acid가 포함된 수용액 (A)와 $0.1 \%$ formic acid가 포함된 Acetonitrile (B)이며 이동상의 유속은 $1 \mathrm{~mL} / \mathrm{min}$, 주입량은 $10 \mu \mathrm{L}$ 이었다. 컬 럼 오븐온도는 $30^{\circ} \mathrm{C}$, 검출기의 흡광도는 203 및 $280 \mathrm{~nm}$ 에서 측정하였다. 이동상 기울기 조건은 $\mathrm{A}\left(\mathrm{H}_{2} \mathrm{O}\right): \mathrm{B}$ (Acetonitrile) $=90: 10$ 에서 $\mathrm{B}$ 를 $10 \%$ 로 5 분간 진행하고, $5-30$ 분간 $\mathrm{B}$ 를 $90 \%$ 로 증가시켰으며, $30-35$ 분간 $\mathrm{B}$ 를 $100 \%$ 로 증가시키고, 이후 35-42 분간 $\mathrm{B}$ 를 다시 $10 \%$ 로 감소시킨 후 $42-55$ 분간 $\mathrm{B}$ 를 $10 \%$ 로 유 지하였다. 분리된 화합물 4종을 메탄올에 용해시켜 표준용액을 제조하였으며, 정량분석의 범위는 $6.25-400 \mathrm{ppm}$ 사이의 5 농도 에서 검량곡선을 작성하였다.

\section{세포 배양}

인간 간암 세포인 HepG2 (KCLB, Seoul, Korea) 세포는 10\% (v/v) FBS를 첨가한 DMEM 배지 (Lonza, Basel, Switzerland) 와 $37^{\circ} \mathrm{C}, 5 \% \mathrm{CO}_{2}, 95 \%$ humid air로 조절된 배양기를 사용하 여 배양하였다.

\section{세포 생존율 시험}

분리된 화합물들의 세포독성 실험은 MTT colorimetric assay 방법을 이용하여 사용하였다[26]. HepG2 세포를 $5 \times 10^{4}$ cells/ $\mathrm{mL}$ 의 농도로 $100 \mu \mathrm{L}$ 씩 96 well plate에 분주하여 배양하였다. 분주 12 시간 후에 화합물을 농도 별로 처리하고 24 시간 후 50 $\mu \mathrm{L}$ 의 MTT $[5 \mathrm{mg} / \mathrm{mL}$ in phosphate buffered saline] 시약을 첨가하여 다시 2시간 동안 배양하였다. 배양이 종료된 후, 배지 를 제거하고 $100 \mu \mathrm{L}$ 의 $\mathrm{DMSO}$ 를 첨가하여 형성된 formazan을 용해하고 Microplate reader (Bio-Tek, Vermont, VT, USA)를 이용하여 $550 \mathrm{~nm}$ 에서 흡광도를 측정하였다. 화합물들의 에탄올 독성 억제효과를 측정하기 위해 HepG2 세포를 $5 \times 10^{4}$ cells $/ \mathrm{mL}$ 의 농도로 $100 \mu \mathrm{L}$ 씩 96 well plate에 분주하고 12시간 후에 $0.5 \mathrm{M}$ 의 에탄올과 현삼화합물을 농도 별로 동시에 처리하였다. 처리 24시간 후 위와 같은 방법으로 MTT assay를 수행하였다. 세포의 생존율은 다음과 같이 계산하였다.

$$
\begin{aligned}
\text { Cell viability }(\%)= & {[\mathrm{OD}(\text { compound })-\mathrm{OD}(\text { Blank }) /} \\
& \mathrm{OD}(\text { control })-\mathrm{OD}(\text { Blank })] \times 100
\end{aligned}
$$

\section{통계처리}

모든 실험 결과는 mean $\pm \mathrm{SD}$ 로 나타내었고 $(n=3)$, 각 실험군 간 차이의 통계적 유의성은 Graph-pad prism 5 software를 이용하 여 ANOVA 분산분석과 Tukey's multiple comparison test로 유의성 검정을 시행하였다 $(p<0.05)$.

\section{결과 및 고찰}

화합물 1는 White amorphous powder 형상으로서 TLC 전개 후, $10 \%$ 황산 발색 시 갈색으로 발색 되었다. 고분해능 질량분 석 장비를 이용하여 측정한 결과, $m / z 493.1718$ [M-H] $]^{-}$peak 의 관측으로 분자식은 $\mathrm{C}_{24} \mathrm{H}_{30} \mathrm{O}_{11}$ (Calcd. $\mathrm{m} / \mathrm{z}$ 494.4884)으로 예 상하였고 질량 값은 $494[\mathrm{M}]^{+}$로 확인하였다(Fig. 2). ${ }^{1} \mathrm{H}-\mathrm{NMR}$ $\left(600 \mathrm{MHz}, \mathrm{CD}_{3} \mathrm{OD}, \delta_{\mathrm{H}}\right)$ spectrum 과 ${ }^{13} \mathrm{C}-\mathrm{NMR}(150 \mathrm{MHz}$, $\mathrm{CD}_{3} \mathrm{OD}, \delta \mathrm{c}$ ) 스펙트럼을 통하여 두 개의 oxygenated quaternary ( $\delta \mathrm{c} 88.8,73.4)$, 하나의 methylene $\left(\delta \mathrm{c} 46.2 ; \delta_{\mathrm{H}} 2.27 / 2.02\right)$ 을 제외하고 화합물 $\mathbf{3}$ (aucubin)과 유사한 iridoid 골격에, 하나의 ester ( $\delta \mathrm{c} 168.7)$, 하나의 aromatic quaternary ( $\delta \mathrm{c} 135.9)$, 다섯 개의 aromatic methine $(\delta \mathrm{c} 131.5,130.0,130.0,129.2,129.2$; $\left.\delta_{\mathrm{H}} 7.59,7.59,7.40,7.40,7.39\right)$, 두 개의 olefin methine $(\delta \mathrm{c}$ $\left.146.1,120.1 ; \delta_{\mathrm{H}} 7.67,6.51\right)$ 을 추가로 관측하여, cinnamic acid 가 하나 결합해 있음을 확인하였다(Table 1). 이를 종합해 서 문헌과 비교한 결과, harpagoside (Fig. 1)로 구조 동정 하였 다[27]. 화합물 2는 White amorphous powder 형상으로서 $\mathrm{TLC}$ 전개 후, $10 \%$ 황산 발색 시 분홍색으로 발색 되었다. 고 분해능 질량분석 장비를 이용하여 측정한 결과, $\mathrm{m} / \mathrm{z} 783.2645$ $[\mathrm{M}-\mathrm{H}]^{-}$peak의 관측으로 분자식은 $\mathrm{C}_{36} \mathrm{H}_{48} \mathrm{O}_{19}$ (Calcd. $\mathrm{m} / z$ 784.7549)으로 예상하였고 질량 값은 $784[\mathrm{M}]^{+}$로 확인하였다 (Fig. 2). ${ }^{1} \mathrm{H}-\mathrm{NMR}\left(600 \mathrm{MHz}, \mathrm{CD}_{3} \mathrm{OD}, \delta_{\mathrm{H}}\right)$ spectrum 과 ${ }^{13} \mathrm{C}-$ $\mathrm{NMR}\left(150 \mathrm{MHz}, \mathrm{CD}_{3} \mathrm{OD}, \delta \mathrm{c}\right)$ 스펙트럼을 통하여 화합물 4 (acteoside)과 매우 유사한 구조에 당이 하나 더 결합했음을 예 상하였다. 당에서 유래한 signal 들의 chemical shift 및 anomer proton signal의 결합정수 $(J=6.6 \mathrm{~Hz})$ 로부터 당의 구조가 $\alpha-\mathrm{L}-$ arabinopyranose 임을 확인하였다. 당의 결합 위치를 확인하기 위하여 $\mathrm{gHMBC}$ 를 확인한 결과, anomer proton $\left(\delta_{\mathrm{H}} 4.19, \mathrm{H}-\right.$ $\left.11^{\prime \prime \prime}\right)$ 이 C-6'의 oxygenated methylene carbon ( $\delta \mathrm{c} 69.1$ )과 cross peak를 보여 $\alpha$-L-arabinopyranose 가 $\beta$-D-glucopyranose 의 6' 


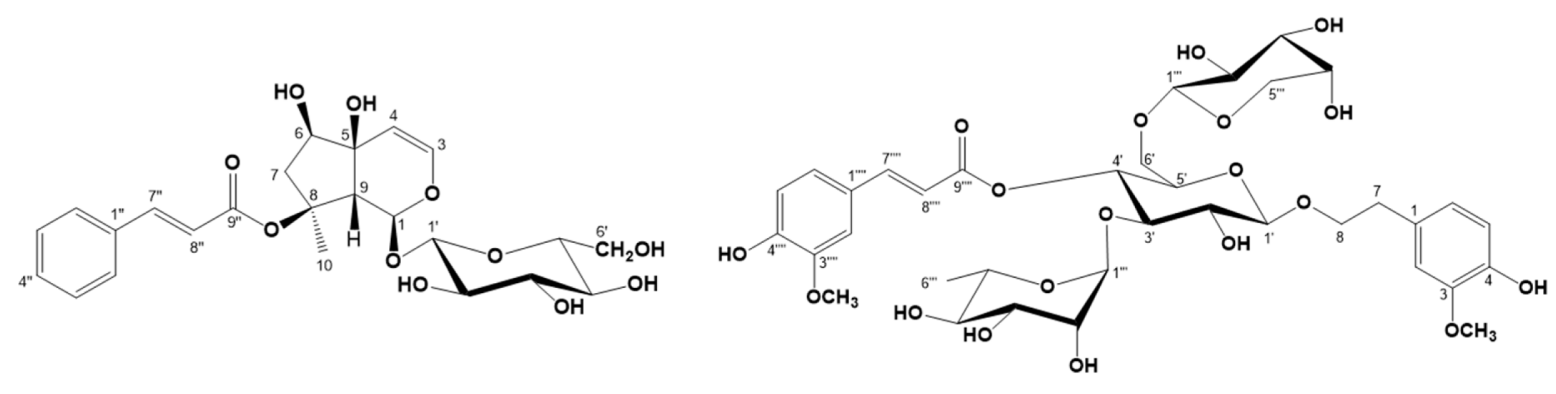

Harpagoside (1)

Angoroside C (2)

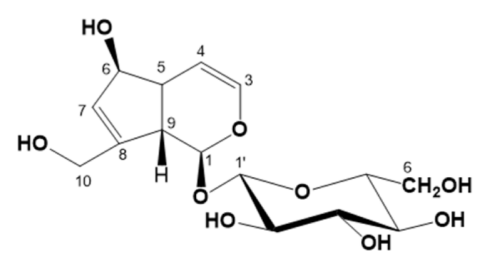

Aucubin (3)

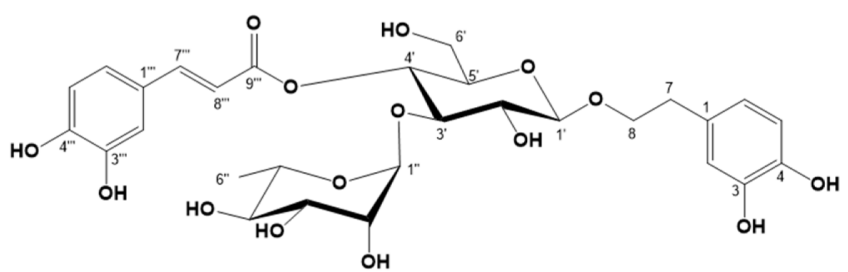

Acetoside (4)

Fig. 1 Chemical structures of compound 1-4 isolated from S. buergeriana

번에 결합하고 있음을 알 수 있었다. 이를 종합해서 문헌과 비 교한 결과, angoroside C (Fig. 1)로 구조 동정 하였다[28].

화합물 3은 White amorphous powder 형상으로서 TLC 전개 후, $10 \%$ 황산 발색 시 갈색으로 발색 되었다. 고분해능 질량분 석 장비를 이용하여 측정한 결과, $m / z 345.1211$ [M-H] $]^{-}$peak의 관측으로 분자식은 $\mathrm{C}_{15} \mathrm{H}_{22} \mathrm{O}_{9}$ (Calcd. $\mathrm{m} / z$ 346.3297)으로 예상하 였고 질량 값은 $346[\mathrm{M}]^{+}$로 확인하였다(Fig. 2). ${ }^{1} \mathrm{H}-\mathrm{NMR}(600$ $\mathrm{MHz}, \mathrm{CD}_{3} \mathrm{OD}, \delta_{\mathrm{H}}$ ) 스펙트럼에서 하나의 oxygenated olefin methine $\left(\delta_{\mathrm{H}} 6.30\right)$, 두 개의 olefin methine $\left(\delta_{\mathrm{H}} 5.76,5.29\right)$ proton signal를 관측하였으며, 하나의 hemiacetal $\left(\delta_{\mathrm{H}} 4.90\right)$, 하 나의 oxygenated methine $\left(\delta_{\mathrm{H}} 4.43\right)$, 하나의 oxygenated methylene $\left(\delta_{\mathrm{H}} 4.34 / 4.18\right)$ proton signal을 관측하였다. 또한 하 나의 hemiacetal $\left[\delta_{\mathrm{H}} 4.68\left(\mathrm{H}-1^{\prime}\right)\right]$, 네 개의 oxygenated methine $\left(\delta_{\mathrm{H}} 3.36,3.27,3.26,3.21\right)$, 그리고 하나의 oxygenated methylene $\left(\delta_{\mathrm{H}} 3.85 / 3.64\right)$ proton signal 로부터 하나의 당이 존재함을 예상 하였다(Table 1). 이를 통해 화합물 3이 iridoid monoglycoside 임을 예상하였다. ${ }^{13} \mathrm{C}-\mathrm{NMR}\left(150 \mathrm{MHz}, \mathrm{CD}_{3} \mathrm{OD}, \delta_{\mathrm{C}}\right)$ 스펙트럼 에서 당으로부터 유래한 signal 들을 제외한 탄소수가 10개임을 확인하였고, 이를 통해 iridoid 임을 확인하였다. 또한 당에서 유 래한 하나의 hemiacetal [ $\delta \mathrm{c} 99.9$ (C-1')], 네 개의 oxygenated methine ( $\delta \mathrm{c} 78.3,77.9,74.9,71.6$ ), 하나의 oxygenated methylene ( $\delta$ c 61.4) carbon signal의 chemical shift 및 anomer proton signal의 결합 정수 $\left(J=7.8 \mathrm{~Hz}, \mathrm{H}-1^{\prime}\right)$ 로부터 세 당의 구조가 $\beta$ D-glucopyranose임을 확인하였다. 결합 위치를 확인하기 위하여 $\mathrm{gHMBC}$ 를 측정한 결과, 하나의 anomer proton $\left(\delta_{\mathrm{H}} 4.86, \mathrm{H}-1^{\prime}\right)$ 이 C-2'의 hemiacetal carbon ( $\delta \mathrm{c}$ 97.77)과 cross peak를 보여 하나의 $\beta$-D-glucopyranose가 1 번에 결합하고 있음을 알 수 있 었다. 또한 하나의 oxygenated methylene proton signal $\left(\delta_{\mathrm{H}}\right.$ $4.34 / 4.18, \mathrm{H}-10)$ 이 C-7의 olefin methine carbon signal $\left(\delta_{\mathrm{C}}\right.$ $130.3)$ 과 cross peak를 보여 ethyl 기가 C-8에 결합해 있음을
확인하였다. 이를 종합해 문헌과 비교한 결과, aucubin (Fig. 1) 으로 구조 동정하였다[29].

화합물 4는 White amorphous powder 형상으로서 TLC 전개 후, $10 \%$ 황산 발색 시 분홍색으로 발색 되었다. 고분해능 질량 분석 장비를 이용하여 측정한 결과, $m / z 623.1945[\mathrm{M}-\mathrm{H}]^{-}$peak 의 관측으로 분자식은 $\mathrm{C}_{29} \mathrm{H}_{36} \mathrm{O}_{15}$ (Calcd. $\mathrm{m} / \mathrm{z}$ 624.5871)으로 예 상하였고 질량 값은 $624[\mathrm{M}]^{+}$로 확인하였다(Fig. 2). ${ }^{1} \mathrm{H}-\mathrm{NMR}$ $\left(600 \mathrm{MHz}, \mathrm{CD}_{3} \mathrm{OD}, \delta_{\mathrm{H}}\right)$ 스펙트럼에서 세 개의 aromatic methine $\left(\delta_{\mathrm{H}} 6.69,6.67,6.57\right)$, 하나의 oxygenated methylene $\left(\delta_{\mathrm{H}} 4.04\right)$, 그리고 하나의 methylene $\left(\delta_{\mathrm{H}} 2.80\right)$ proton signal을 통해 하나 의 hydroxytyrosol 이 존재함을 예상하였고, 세 개의 aromatic methine $\left(\delta_{\mathrm{H}} 7.05,6.96,6.78\right)$ 과 두 개의 olefin methine $\left(\delta_{\mathrm{H}}\right.$ $7.59,6.27)$ proton signal을 통해 하나의 caffeic acid 가 존재 함을 예상하였다. 또한 두 개의 hemiacetal [ $\delta_{\mathrm{H}} 5.19$ (H-1"), $\left.4.38\left(\mathrm{H}-1^{\prime}\right)\right]$, 여덟 개의 oxygenated methine $\left(\delta_{\mathrm{H}} 4.92,4.04\right.$, $3.91,3.81,3.57,3.54,3.39,3.29)$, 하나의 oxygenated methylene $\left(\delta_{\mathrm{H}} 3.62 / 3.52\right)$, 그리고 하나의 methyl $\left(\delta_{\mathrm{H}} 1.09\right)$ proton signal 로부터 각각 다른 두개의 당이 존재함을 예상하였다(Table 2). 이를 통해 이 화합물이 phenylethanoid glycoside임을 예상하였 다. ${ }^{13} \mathrm{C}-\mathrm{NMR}\left(150 \mathrm{MHz}, \mathrm{CD}_{3} \mathrm{OD}, \delta_{\mathrm{C}}\right)$ 스펙트럼에서 당으로부 터 유래한 signal 들을 제외한 탄소수가 17 개임을 확인하였고, 이를 통해 하나의 hydroxytyrosol 과 하나의 caffeic acid가 존 재함을 확인하였다. 또한 당에서 유래한 두 개의 hemiacetal [äc 104.2 (C-1'), 103.1 (C-1")], 여덟 개의 oxygenated methine (äc 81.6, 76.3, 76.1, 73.9, 72.5, 72.4, 70.7, 70.6), 하나의 oxygenated methylene ( $\delta \mathrm{c} 62.4)$, 그리고 하나의 methyl $(\delta \mathrm{c}$ 18.6) carbon signal의 chemical shift 및 anomer proton signal 의 결합 정수 $\left(J=8.4 \mathrm{~Hz}, \mathrm{H}-1^{\prime}, J=1.8 \mathrm{~Hz}, \mathrm{H}-1^{\prime \prime \prime}\right)$ 로부터 두 당 의 구조가 $\beta$-D-glucopyranose와 $\alpha$-L-rhamnopyranose 임을 확인 하였다. Kim 등의[30] 연구에서 일반적으로 $\beta$-D-glucopyranose 
(A)

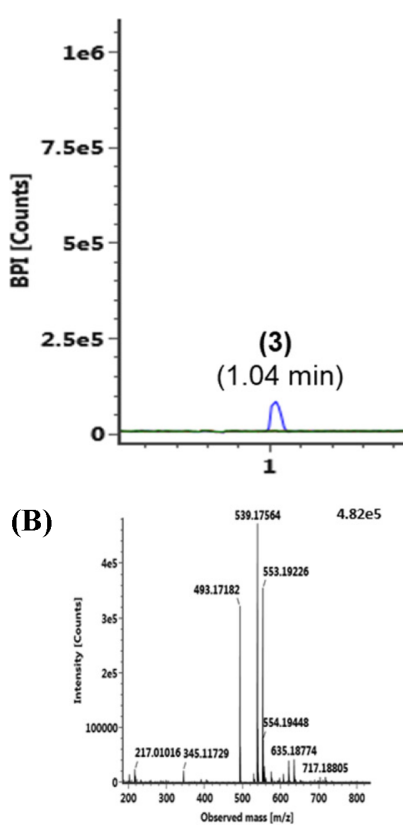

(1)
(2)

(5.36 $\mathrm{min})$

(4)

(4.50 $\mathrm{min})$
(1)

(6.79 $\mathrm{min})$

(1)

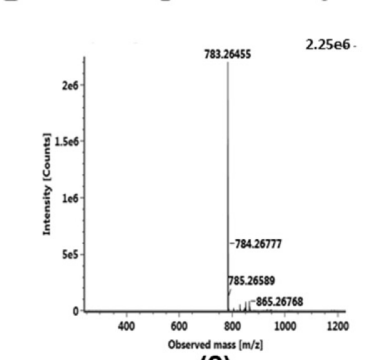

(2)

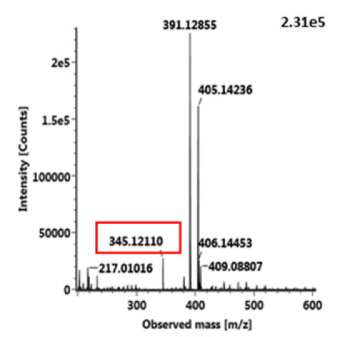

(3)

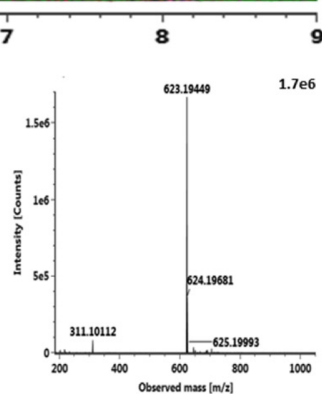

(4)

Fig. 2 Ion chromatogram of compounds 1-4 (A) by UPLC-QTOF/MS in negative-ion mode. (B) High resolution mass spectra of harpagoside (1) angoroside C (2) aucubin (3), and acetoside (4)

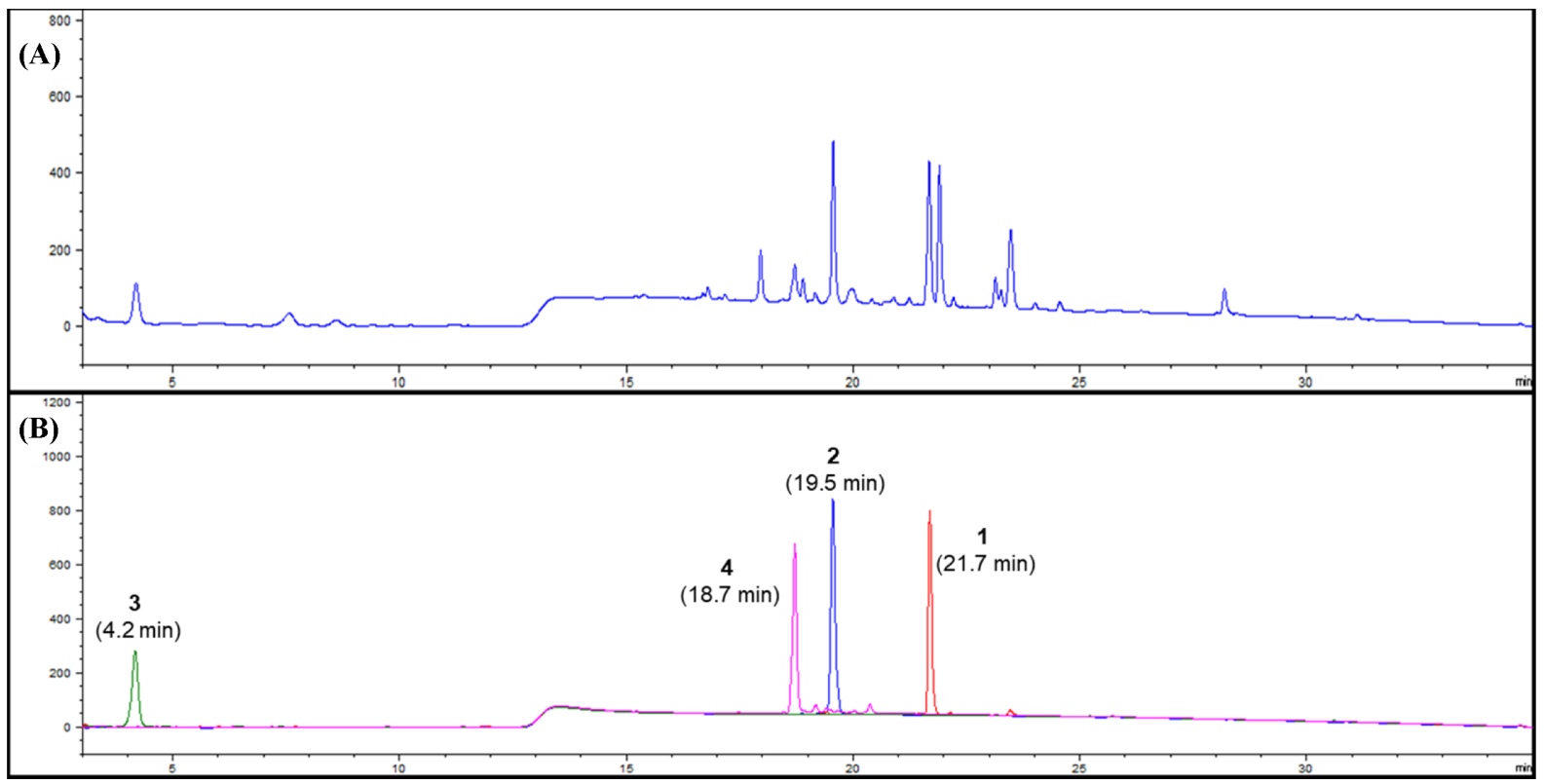

Fig. 3 HPLC analysis of roots of S. buergeriana. (A) Chromatogram of the extraction of roots of S. buergeriana at $280 \mathrm{~nm}$ and (B) Separation of a standard mixture of compounds 1-4. [harpagoside (1), angoroside C (2), aucubin (3) and acetoside (4)]

의 C-3의 carbon signal은 대개 $78.7 \mathrm{ppm}$ 에서 관측되나, $\delta_{\mathrm{C}}$ 81.6까지 저자장으로 이동한 것으로 보아 $\alpha$-L-rhamnopyranose 가 $\beta$-D-glucopyranose의 C-3의 수산기와 결합하여 glycosidation shift가 일어난 것임을 알 수 있었다. 결합 위치를 확인하기 위 하여 $\mathrm{gHMBC}$ 를 측정한 결과, 하나의 anomer proton $\left(\delta_{\mathrm{H}} 4.38\right.$, $\left.\mathrm{H}-1^{\prime}\right)$ 이 C-8의 oxygenated methylene carbon ( $\left.\delta \mathrm{c} 72.1\right)$ 과 cross peak를 보여 하나의 $\beta$-D-glucopyranose가 hydroxytyrosol 의 8 번에 결합하고 있음을 알 수 있었다. 또한 하나의 oxygenated methine proton $\left(\delta_{\mathrm{H}} 4.92, \mathrm{H}^{-} 4^{\prime}\right)$ 이 C-9"의 ester carbon $(\delta \mathrm{c}$ 168.4)과 cross peak를 보여 caffeic acid가 $\beta$-Dglucopyranose의 4 번에 결합하고 있음을 알 수 있었다. 다른 하 나의 anomer proton $\left(\delta_{\mathrm{H}} 5.19, \mathrm{H}-1^{\prime \prime \prime}\right)$ 이 C-3'의 oxygenated methine 
Table 2 Quantification of 70\% EtOH extracts from S. buergeriana compounds 1-4 by HPLC-UV analysis

\begin{tabular}{|c|c|c|c|c|c|c|}
\hline Compounds & Calibration Curves & $r^{2}$ & Linear range (ppm) & Content (mg/g) & $\mathrm{LOD}^{1)}(\mathrm{ng} / \mu \mathrm{L})$ & $\mathrm{LOQ}^{2)}(\mathrm{ng} / \mu \mathrm{L})$ \\
\hline Harpagoside (1) & $y=145.28 x-411.58$ & 0.989 & $0.19-200$ & 11.5 & 2.85 & 2.90 \\
\hline Angoroside C (2) & $y=11.583 x-4.8857$ & 0.999 & $0.39-100$ & 7.6 & 0.68 & 1.29 \\
\hline Aucubin (3) & $y=0.0886 x+0.4503$ & 0.998 & $19.53-312.5$ & 41.2 & 28.78 & 107.78 \\
\hline Acetoside (4) & $y=35.879 x-2.5453$ & 0.998 & $0.39-25$ & 4.8 & 0.01 & 0.21 \\
\hline
\end{tabular}

${ }^{1} \mathrm{LOD}$; Limit of detection, ${ }^{2} \mathrm{LOQ}$; Limit of quantification

(A)

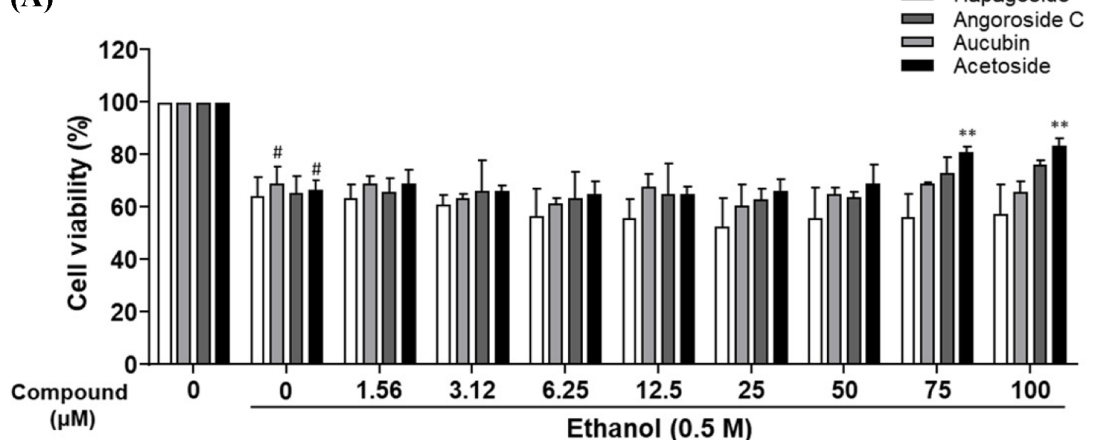

(B)

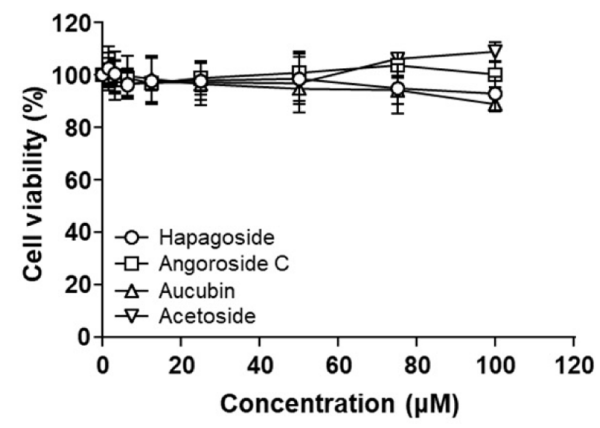

Fig. 4 Effect of compounds on the cytotoxicity in ethanol-damaged HepG2 cells. (A) HepG2 cells were treated with 0.5 M ethanol and various concentrations of compounds for $24 \mathrm{~h}$. (B) HepG2 cells were treated with various concentrations of compounds for $24 \mathrm{~h}$. Cell viability was measured using MTT assay. Values are expressed as the mean \pm SD. ${ }^{*} p<0.001$; control $v s$. ethanol only treated HepG 2 cells, $* * p<0.01$; ethanol only treated HepG2 cells $v s$. ethanol and compound-treated HepG2 cells

carbon ( $\delta \mathrm{c}$ 81.6) cross peak를 보여 $\alpha$-L-rhamnopyranose가 $\beta$ D-glucopyranose의 3 번에 결합하고 있음을 확인하였다. 이를 종 합해서 문헌과 비교한 결과, acetoside (Fig. 1)로 구조 동정 하 였다[31].

화합물 4종의 정량분석을 위해 UV 검출기가 장착된 HPLC 를 사용하여 크로마토그램을 분석하였다. 최적의 용매 기울기 조건을 확립하고 분석된 결과의 머무름 시간을 비교하였을 때, harpagoside (1)는 21.7분, angoroside $C$ (2)는 19.5분, aucubin (3)는 4.2분, acetoside (4)는 18.7분에서 검출되었다(Fig. 3). 검 량 곡선은 표준물질의 5농도 범위 안에서 측정된 값을 회기 분 석을 통해 작성하였다. 상관계수 $\left(r^{2}\right)$ 는 화합물 4종에 대해 각각 0.989 (1), 0.999 (2), 0.998 (3) 및 0.998 (4)로 매우 높은 값 을 보여주었다. 현삼에서 분리한 4종의 화합물의 함량분석한 결 과, $11.5 \mathrm{mg} / \mathrm{g}$ (1), $7.6 \mathrm{mg} / \mathrm{g}$ (2), $41.2 \mathrm{mg} / \mathrm{g}$ (3), 및 $4.8 \mathrm{mg} / \mathrm{g}$ (4)으로 확인되었으며 4종의 화합물 중 aucubin이 함량이 높았 고 acetoside는 함량이 상대적으로 낮게 나왔다(Table 2).

현삼에서 분리한 단일 화합물 4종의 간세포에 대한 독성을 평가하기 위해 MTT assay를 수행한 결과, 화합물 모두 HepG2 $(100 \mu \mathrm{M})$ 세포에 대한 독성을 나타내지 않는 것을 확인하였다 (Fig. 4B), 세포손상을 유발하기 위하여 알코올 $(0.5 \mathrm{M})$ 를 처리하 여 독성 유발에 따른 세포의 손상 또는 세포 사멸에 대한 화합 물의 간세포 보호효과를 확인하기 위해 알코올 처리에 따른 세 포 생존율의 변화를 확인한 결과, 알코올 처리군은 정상 대조 군 $(100 \%)$ 과 비교하여 세포 생존율이 약 $42.2 \%$ 까지 감소하였 다. 알코올 처리 후 화합물 2, 4의 처리군은 각각 $74.2 \%$ (2) 및 $82.1 \%$ (4)의 세포 생존율을 나타났었고, 알코올 처리군과 비 교 시 각각 $31.2 \%$ (2) 및 $50 \%$ (4)의 증가율을 보였다(Fig. 4A).
Mostafa 등[32] 연구에 의하면 angoroside C는 항산화 활성 이 보고되어 있으며, $\mathrm{Li}$ 등[33] 연구에서는 acetoside 성분이 $\mathrm{H}_{2} \mathrm{O}_{2}$ 로 유도된 신경세포 사멸을 억제하는 것으로 보고되어 있 다. 현삼에서 분리한 phenylethananoid 중 angoroside $\mathrm{C}$ 의 간세 포 보호 활성 및 화합물들의 함량분석은 이번 연구에서 처음 보고하였다. 활성 화합물의 간세포 보호효과의 작용 기작 규명 을 위해서 분자생물학적인 접근방법을 통한 기전 연구 및 동물 모델을 이용한 in vivo 연구가 필요할 것으로 사료된다.

\section{초 록}

현삼(Scrophularia buergeriana) 뿌리를 $80 \%$ Methanol수용액으 로 추출한 뒤, 감압 농축한 추출물을 EtOAc, $n-\mathrm{BuOH}$ 과 $\mathrm{H}_{2} \mathrm{O}$ 층으로 계통 분획을 실시하였다. $n$ - $\mathrm{BuOH}$ 분획에 대하여 silica gel, octadecyl $\mathrm{SiO}_{2}$ column chromatograph 및 중압분취(MPLC) 장비를 반복 실시하여 4종의 phenylethanoid glycoside 및 iridoid glycoside계의 화합물을 분리하였다. NMR 및 Mass데이 터를 해석하여, harpagoside (1), angoroside C (2), aucubin (3) 및 acetoside (4)로 구조 동정하였다. 분리한 4종의 화합물 에 대하여 HPLC 분석법을 이용하여 정량분석한 결과, 11.5 $\mathrm{mg} / \mathrm{g}$ (1), $7.6 \mathrm{mg} / \mathrm{g}$ (2), $41.2 \mathrm{mg} / \mathrm{g}$ (3), 및 $4.8 \mathrm{mg} / \mathrm{g}$ (4) 이 현삼 뿌리에 함유된 것을 확인하였다. 현삼으로부터 분리된 화 합물 중 angoroside C 및 acetoside는 에탄올에 의해 저해된 세 포 성장률을 검증한 결과, 간암세포종인 $\mathrm{HepG} 2$ 세포에 대해서 간세포를 보호하는 효과가 있음을 확인하였다. 
Keywords 정량분석 · 현삼 · HepG2 · Iridoid · Phenylpropanoid 감사의 글 본 논문은 농촌진흥청 차세대바이오그린 21 연구사업(과제번호: PJ01321502)의 지원에 의해 이루어진 것으로 이에 감사드립니다.

\section{References}

1. Lee JH, Park SM, Kim YC, Woo HJ (2001) A clinical study of the effects of Chungganhaeju-tang on alcoholic fatty liver. J Korean Med 22(4): 107-113

2. Baik TH (2016) A case study on a patient with non-alcoholic fatty liver disease (NAFLD) by using ultrasound. J Korean Med 37(1): 151-157

3. Kwon TD (2007) The effects of exercise on hepatotoxicity in mice with alcoholic fatty liver. Gene Expr 11(3): 257-264

4. Park SU, Li X, Eom SH, Lee CY, Lee SY (2010) E-p-methoxycinnamic acid production in hairy root cultures of Scrophularia buergeriana Miquel. Arch Biol Sci 62: 649-652

5. Herbal Medicine School Compilation Committee (2013) Pharmacognosy. Dongmyeong Publisher, Gyeonggi-do, Korea, p 224

6. Lee HW, Park SY, Choo BK, Chun JM, Lee AY, Kim HK (2007) Quantitative analysis comparison of korea and china Scrophulariae radix. Kor J Pharmacogn 38(1): 15-18

7. Kim HM, Ahn MJ, SH Lee (2012) Isolation and identification of phytochemical constituents from Scrophularia takesimensis. J Med Plants Res 6(22): 3923-3930

8. Kim SH, Kim DH, Park JH, Choi EJ, Park SH, Lee KY, Jeon MJ, Kim YC, Sung SH (2010) Discrimination of Scrophularia spp. according to geographic origin with HPLC-DAD combined with multivariate analysis. Microchem J 94(2): 118-124

9. Lee MK, Choi OG, Park JH, Cho HJ, Ahn MJ, Kim SH, Kim YC, Sung SH (2007) Simultaneous determination of four active constituents in the roots of Scrophularia buergeriana by HPLC-DAD and LC-ESI-MS. J Sep Sci 30(15): 2345-2350

10. Lee HJ, Spandidos DA, Tsatsakis A, Margina D, Izotov BN, Yang SH (2019) Neuroprotective effects of Scrophularia buergeriana extract against glutamate-induced toxicity in SH-SY5Y cells. Int J Mol Med 43(5): 2144-2152

11. Jeong EJ, Ma CJ, Lee KY, Kim SH, Sung SH, Kim YC (2009) KD-501, a standardized extract of Scrophularia buergeriana has both cognitiveenhancing and antioxidant activities in mice given scopolamine. J Ethnopharmacol 121(1): 98-105

12. Park KH, Ham IH, Choi HY (2008) Hypotensive effect of Scrophularia buergeriana and gene analysis of Scrophularia Species. Kor J Herbology 23(2): 213-223

13. Kim SG (2017) Inhibitory effects of Scrophulariae radix on $\beta$ hexosaminidase release and cytokine production in RBL-2H3 cells. Kor J Herbology 32(6): 9-15

14. Byun SH, Yang CH, Kim SC (2005) Inhibitory effect of Scrophulariae Radix extract on TNF- $\alpha$, IL-1 $\beta$, IL- 6 and nitric oxide production in lipopolysaccharide-activated RAW 264.7 cell. Kor J Herbology 20(2): 716

15. Shin H, Medriano CA, Park B, Park YH, Lee KY (2018) Screening and identification of neuroprotective compounds from Scrophularia buergeriana using cell extraction coupled with LC-MS. J Pharm Biomed Anal 148: $355-360$
16. Lv PY, Feng H, Huang WH, Tian YY, Wang YQ, Qin YH, Li XH, Hu K, Zhou HH, Ouyang DS (2017) Aucubin and its hydrolytic derivative attenuate activation of hepatic stellate cells via modulation of TGF- $\beta$ stimulation. Environ Toxicol Pharmacol 50: 234-239

17. Lin SJ, Jiang SH, Li YM, Zeng JF, Zhu DY (2000) Two novel iridoids from Scrophularia buergeriana. Tetrahedron Lett 41(7): 1069-1071

18. Wu XM, Zhang LQ, Chen XC, Feng L, Xing WX, Li YM (2014) A new iridoid derivative from the roots of Scrophularia buergeriana. Acta Pharmacol Sin 49(7): 1019-1021

19. Kim SR, Lee KY, Koo KA, Sung SH, Lee NG, Kim JW, Kim YC (2002) Four new neuroprotective iridoid glycosides from Scrophularia buergeriana Roots. J Nat Prod 65(11): 1696-1699

20. Jeong EJ, Lee KY, Kim SH, Sung SH, Kim YC (2008) Cognitiveenhancing and antioxidant activities of iridoid glycosides from Scrophularia buergeriana in scopolamine-treated mice. Eur J Pharmacol 588(1): 78-84

21. Tundis R, Loizzo MR, Menichini F, Statti GA, Menichini F (2008) Biological and pharmacological activities of iridoids: recent developments. Mini Rev Med Chem 8(4): 399-420

22. Zhang L, Zhu T, Qian F, Xu J, Dorje G, Zhao Z, Guo FJ, Li Y (2014) Iridoid glycosides isolated from Scrophularia dentata Royle ex Benth. and their anti-inflammatory activity. Fitoterapia 98: 84-90

23. Kim SR, Kim YC (2000) Neuroprotective phenylpropanoid esters of rhamnose isolated from roots of Scrophularia buergeriana. Phytochem 54(5): 503-509

24. Díaz AM, Abad MJ, Fernández L, Silván AM, De Santos J, Bermejo P (2004) Phenylpropanoid glycosides from Scrophularia scorodonia: In vitro anti-inflammatory activity. Life Sci 74(20): 2515-2526

25. Carvalho AA, Andrade LN, de Sousa ÉBV, de Sousa DP (2015) Antitumor phenylpropanoids found in essential oils. Biomed Res Int. doi: $10.1155 / 2015 / 392674$

26. Skehan P, Storeng R, Scudiero D, Monks A, McMahon J, Vistica D, Warren JT, Bokesch H, Kenney S, Boyd MR (1990) New colorimetric cytotoxicity assay for anticancer-drug screening. J Nat Cancer Inst 82(13): 1107-1112

27. Li YM, Jiang SH, Gao WY, Zhu DY (1999) Iridoid glycosides from Scrophularia ningpoensis. Phytochem 50(1): 101-104

28. de Santos J, Lanza AMD, Fernández L, Rumbero A (2000) Isoangoroside $\mathrm{C}$, a phenylpropanoid glycoside from Scrophularia scorodonia roots. Z Naturforsch C 55(5-6): 333-336

29. Ersöz T, Berkman MZ, Taşdemir D, Çaliş İ, Ireland CM (2002) Iridoid and phenylethanoid glycosides from Euphrasia pectinata. Turk J Chem 26(2): 178-188

30. Kim HG, Oh HJ, Ko JH, Song HS, Lee YG, Kang SC, Lee DY, Baek NI (2019) Lanceoleins A-G, hydroxychalcones, from the flowers of Coreopsis lanceolata and their chemopreventive effects against human colon cancer cells. Bioorg Chem 85: 274-281

31. Andary C, Wylde R, Laffite C, Privat G, Winternitz F (1982) Structures of verbascoside and orobanchoside, caffeic acid sugar esters from Orobanche rapum-genistae. Phytochem 21(5): 1123-1127

32. Mostafa M, Nahar N, Mosihuzzaman M, Makhmoor T, Choudhary MI, Rahman AU (2007) Free radical scavenging phenylethanoid glycosides from Leucas indica Linn. Nat Prod Res 21(4): 354-361

33. Li M, Xu T, Zhou F, Wang M, Song H, Xiao X, Lu B (2018) Neuroprotective effects of four phenylethanoid glycosides on $\mathrm{H}_{2} \mathrm{O}_{2}$ induced apoptosis on PC-12 cells via the Nrf2/ARE pathway. Int J Mol Sci 19(4): 1135 